\title{
Leptin induces epithelial-to-mesenchymal transition via activation of the ERK signaling pathway in lung cancer cells
}

\author{
MIN XU ${ }^{1 *}$, FA-LE CAO $^{2 *}$, NAIYI LI $^{3}$, XIN GAO $^{1}$, XUEJIA SU $^{4}$ and XIAOLING JIANG ${ }^{5}$ \\ Departments of ${ }^{1}$ Nephrology, ${ }^{2}$ Neurology, ${ }^{3}$ Medical Service, ${ }^{4}$ Thoracic Surgery and ${ }^{5}$ Pathology, \\ The 88th Hospital of People's Liberation Army, Taian, Shandong 271000, P.R. China
}

Received November 15, 2017; Accepted June 28, 2018

DOI: $10.3892 / \mathrm{ol} .2018 .9230$

\begin{abstract}
Previous studies revealed that leptin induces the growth and proliferation and inhibits the apoptosis of lung cancer cells. However, the effect of leptin on epithelial-tomesenchymal transition (EMT) is not yet clear. In the present study, the effect of leptin on EMT was investigated as well as its underlying mechanisms in A549 cells. The ability of leptin to induce EMT was investigated by microscopic examination and western blotting. The impacts of leptin on cell migration, invasion and tumorigenesis were evaluated by wound healing, Transwell and colony formation assays, respectively. It was demonstrated that leptin induced EMT-associated morphological changes, namely a decrease in cell-cell contact and a more elongated morphological shape. Leptin decreased the expression levels of epithelial phenotype markers E-cadherin and keratin, increased the expression of mesenchymal phenotype marker Vimentin, and raised the expression of EMT-induced transcription factor ZEB-1. In addition, leptin activated the extracellular signal regulated kinase (ERK) signaling pathway and did not affect the activation of the protein kinase B signaling pathway in A549 cells. Leptin also promoted EMT-induced migration, invasion and tumorigenesis in vitro in A549 cells. The present study provides evidence that leptin induced EMT via the activation of the ERK signaling pathway and increased EMT-induced tumor phenotypes in lung cancer cells. These findings suggest that leptin may be a promising target for lung cancer treatment through the regulation of EMT.
\end{abstract}

Correspondence to: Dr Min Xu, Department of Nephrology, The 88th Hospital of PLA, 6 Hongmen Road, Taian, Shandong 271000, P.R. China

E-mail: xumin022@163.com

*Contributed equally

Abbreviations: EMT, epithelial-to-mesenchymal transition; NSCLC, non-small cell lung cancer; FCS, fetal calf serum; TGF- $\beta$, transforming growth factor- $\beta$; EGF, epidermal growth factor

Key words: leptin, epithelial-to-mesenchymal transition, extracellular signal regulated kinase, invasion, metastasis, tumorigensis

\section{Introduction}

Lung cancer, one of the most aggressive tumors with a high incidence rate, is the leading cause of cancer-associated mortality both worldwide and in China (1). Nearly $85 \%$ of all lung cancer cases are classified as non-small cell lung cancer (NSCLC) and its 5-year survival rate does not often reach $15 \%$ (2). In clinic, according to the histological characteristics, NSCLC is divided into 3 types, including adenocarcinoma, squamous cell carcinoma, and large cell lung cancer (3). At present, $>70 \%$ of NSCLC patients exhibiting metastases to the regional lymph nodes or to distant sites, are at advanced stages at diagnosis (4). Therefore, it is urgent to investigate the targets and explore the mechanisms of NSCLC for early diagnosis and comprehensive treatment.

The metastatic process of cancer can be categorized into 3 stages, namely, tumor cell invasion into surrounding tissue, intravasation into blood or lymphatic vessels, and extravasation into a new host environment (5-7). Epithelial-to-mesenchymal transition (EMT), the ability of epithelial cells to convert from a polarized morphology to a loose mesenchymal phenotype, plays an important role in the process of cancer metastases (8). Accumulating evidence shows that EMT occurs through numerous cellular and molecular alterations, including a gain of Vimentin and Fibronectin expression, and loss of E-cadherin and Keratin at the cell membrane $(9,10)$. Moreover, EMT allows the transient cells to have increased cell mobility, tumor invasion and metastatic dissemination and to be more resistant to cytotoxic drugs (11). Secreted growth factors, notably transforming growth factor- $\beta$ (TGF- $\beta$ ) and epidermal growth factor (EGF), can lead to the activation of EMT of cancer cells through the activation of downstream pathways, such as PI3K/AKT, ERK/MAPK and Smad pathways.

Leptin, encoded by the $o b$ gene on chromosome 7, is a $17 \mathrm{kDa}$ protein composed of 167 amino acids, which primarily regulates appetite and weight. Furthermore, leptin is also considered to play a role in the pathogenesis of several cancer types, including breast and thyroid cancer, hepatocellular carcinoma, colorectal and pancreatic cancer (12-20). With regards to lung cancer, studies have mainly focused on the role of leptin in the carcinogenesis and proliferation of lung cancer cells. However, few studies have investigated the association between leptin and the metastasis of lung cancer. A previous study demonstrated that leptin is differentially expressed in 
lung cancer tissues that do not occur or metastasize, and the expression of leptin is increased in lung cancers with bone metastasis (21), indicating that the leptin pathway may be involved in the metastasis of lung cancer. However, the effect and mechanisms of leptin on metastasis of lung cancer have not yet been fully elucidated.

The present study, therefore, examined the effect of leptin on EMT, a crucial stage in the metastatic process, and explored the underlying molecular mechanisms in A549 lung cancer cells. Our results demonstrated that leptin promoted EMT and regulated the expressions of EMT-related markers and transcription factors through the activation of the ERK signaling pathway. Furthermore, leptin promoted EMT-induced migration and invasion in A549 lung cancer cells.

\section{Materials and methods}

Reagents and antibodies. Leptin was obtained from the leptin protein (Sigma-Aldrich, St. Louis, MO, USA). Antibodies against human E-cadherin, Vimentin, Keratin, Fibronectin, ZEB-1 and Twist were purchased from the Cell Signaling Technology, Inc. (Danvers, MA, USA). Antibodies for p-ERK, total-ERK, p-AKT, total-AKT and $\beta$-actin were obtained from EMD Millipore (Billerica, MA, USA). Matrigel (BD Biosciences, Franklin Lakes, NJ, USA), 24-well Transwell inserts, 6-well and 96-well plates (both from Corning Corp, Corning, NY, USA) were used.

Cell culture and grouping. A549 cell line [obtained from the American Type Culture Collection (ATCC) Rockville, MD, USA] was maintained in RPMI-1640 medium. The medium was supplemented with $10 \%$ fetal calf serum (FCS), $100 \mathrm{U} / \mathrm{ml}$ of penicillin and $100 \mathrm{U} / \mathrm{ml}$ of streptomycin and all the cells were kept at $37^{\circ} \mathrm{C}$ in a humidified atmosphere containing $5 \%$ $\mathrm{CO}_{2}$ and $95 \%$ air. Cells were divided into the following groups: i) Control group $(n=6)$, cells were treated under normal conditions; ii) leptin group $(n=6)$, cells were treated with leptin (100 ng/ml) for the indicated time period; and iii) TGF- $\beta 1$ group $(n=6)$, cells were treated with TGF- $\beta 1(5 \mathrm{ng} / \mathrm{ml})$ for the indicated time period.

Western blotting. After protein quantitation using a Coomassie brilliant blue assay, $50 \mu \mathrm{g}$ protein was boiled in loading buffer, resolved on $10 \%$ SDS-polyacrylamide gels, electrotransferred to nitrocellulose membranes, and probed with antibodies against E-cadherin $(1: 2,500)$, Keratin $(1: 1,000)$, Fibronectin (1:1,000), Vimentin (1:1,000), ZEB-1 (1:200), Twist (1:200), p-ERK (Thr 202/Tyr 204, 1:500), p-AKT (Ser 473, 1:200), total-ERK (1:500), total-AKT $(1: 500)$ and $\beta$-actin $(1: 1,000)$ overnight. The secondary antibody (anti-mouse or anti-rabbit IgG peroxidase conjugated; 1:1,000) was incubated with the membranes and the relative content of target proteins was detected by chemiluminescence.

Wound healing assay. For the wound-healing assay, cells were plated into 6-well plates and grown under normal conditions. When cells grew into a monolayer, a plastic pipette tip was drawn across the center of the plate to produce a clean 1-mm-wide wound area after the cells reached confluency. Then, cells were cultured in medium with $1 \%$ FCS for $24 \mathrm{~h}$.
The cell movement into the wound area was examined by a phase-contrast microscope.

Matrigel invasion assay. The invasion assay was carried out using a Transwell plate (Corning Costar Corp.) precoated with Matrigel (BD Biosciences). Briefly, the Transwell plate was placed on a 24-well plate, and $400 \mu \mathrm{l}$ culture medium (10\% FCS) was added to the lower chamber as a chemoattractant. Then, $200 \mu \mathrm{l}$ cells $\left(1 \times 10^{5}\right)$ suspended in culture medium with $1 \%$ FCS were added to the upper chamber. Cells in the invasion chambers were incubated in a humidified incubator for $24 \mathrm{~h}$. The cells that traversed the membrane pore and spread to the lower surface of the filters were stained with $5 \%$ Giemsa solution for visualization. Cell invasion viability was expressed as a percentage of the value of the control group.

Colony formation assay. A soft agar colony formation assay was performed to assess the anchorage-independent growth ability of cells as a characteristic of in vitro tumorigenicity. Briefly, A549 cells were detached and plated on $0.3 \%$ agarose with a $0.5 \%$ agarose underlay in 6 -wells $\left(1.0 \times 10^{4}\right.$ cells/well). The number of foci $(>100 \mu \mathrm{m})$ were counted after 17 days. Each experiment was performed in triplicate.

Statistical analysis. Each experiment was repeated at least 3 times. Bands from western blotting were quantified by Quantity One software (Bio-Rad Laboratories, Inc., Hercules, CA, USA). Relative protein levels were calculated by referring them to the amount of actin. Data are expressed as the mean \pm standard error of the mean. The difference between means was analyzed by one-way analysis of variance, followed by a Dunnett's test for multiple comparisons. All statistical analyses were performed using SPSS 11.0 software (SPSS, Inc., Chicago, IL, USA). A statistical difference was accepted as significant if $\mathrm{P}<0.05$.

\section{Results}

Leptin induces morphological changes of EMT in A549 cells. It has been reported that A549 cells undergo EMT phenotypic changes when cells are exposed to TGF- $\beta 1(22,23)$. As a result, we used TGF- $\beta 1$ as a positive control and to see if leptin also induced EMT in A549 cells. After exposure to leptin or TGF- $\beta 1$ for $48 \mathrm{~h}$, we found that A549 cells in the two groups all changed to a mesenchymal phenotype, as revealed by an elongated and disseminated appearance (Fig. 1). These findings indicated that leptin induced EMT in A549 cells.

Leptin regulates the expression levels of EMT markers in A549 cells. To further confirm that leptin could lead to EMT, the expression levels of EMT-related markers were measured by western blotting. As shown in Fig. 2, compared with the control group, both leptin and TGF- $\beta 1$ downregulated the expression levels of epithelial phenotype markers E-cadherin and Keratin (Fig. 2A and B). TGF- $\beta 1$ also upregulated the expression levels of mesenchymal phenotype markers Fibronectin and Vimentin (Fig. 2C and D). Meanwhile, leptin did not change the expression of Fibronectin, but significantly increased Vimentin expression in A549 cells (Fig. 2C and D). 

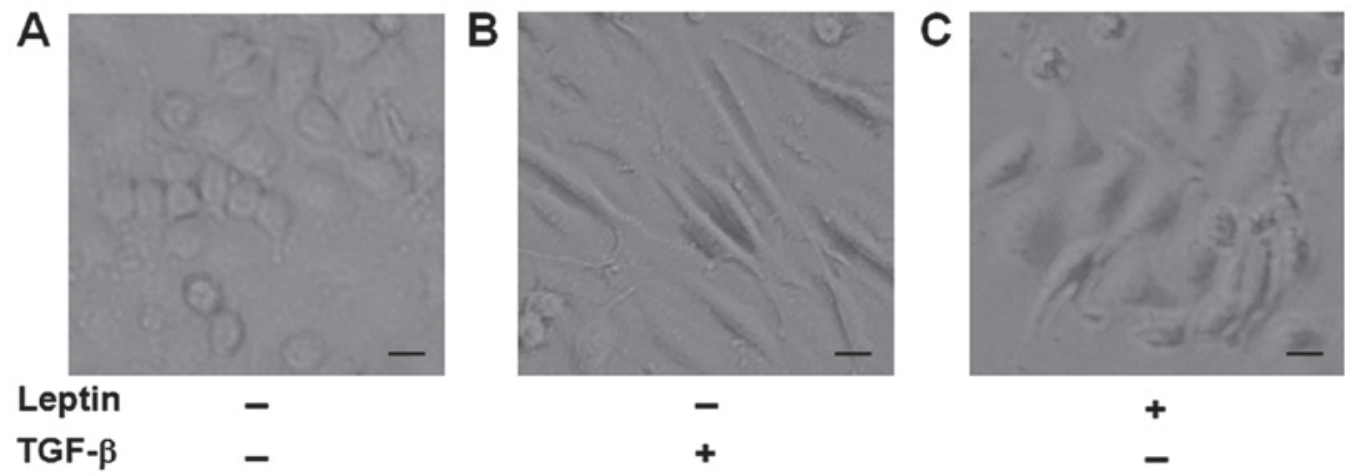

Figure 1. Leptin induces morphological changes of epithelial-to-mesenchymal transition in A549 cells. (A) Control group. A549 cells display classical epithelial morphology, a pebble-like shape and tight cell-cell adhesion. (B) TGF- $\beta 1$ and (C) leptin groups. A549 cells were treated with TGF- $\beta 1$ (5 ng/ml) or leptin $(100 \mathrm{ng} / \mathrm{ml})$ for $48 \mathrm{~h}$ and morphological changes were evaluated under a microscope. A549 cells had a decrease in cell-cell contacts and adopt a more elongated morphological shape. Scale bar, $20 \mu \mathrm{m}$. TGF, tumor growth factor.
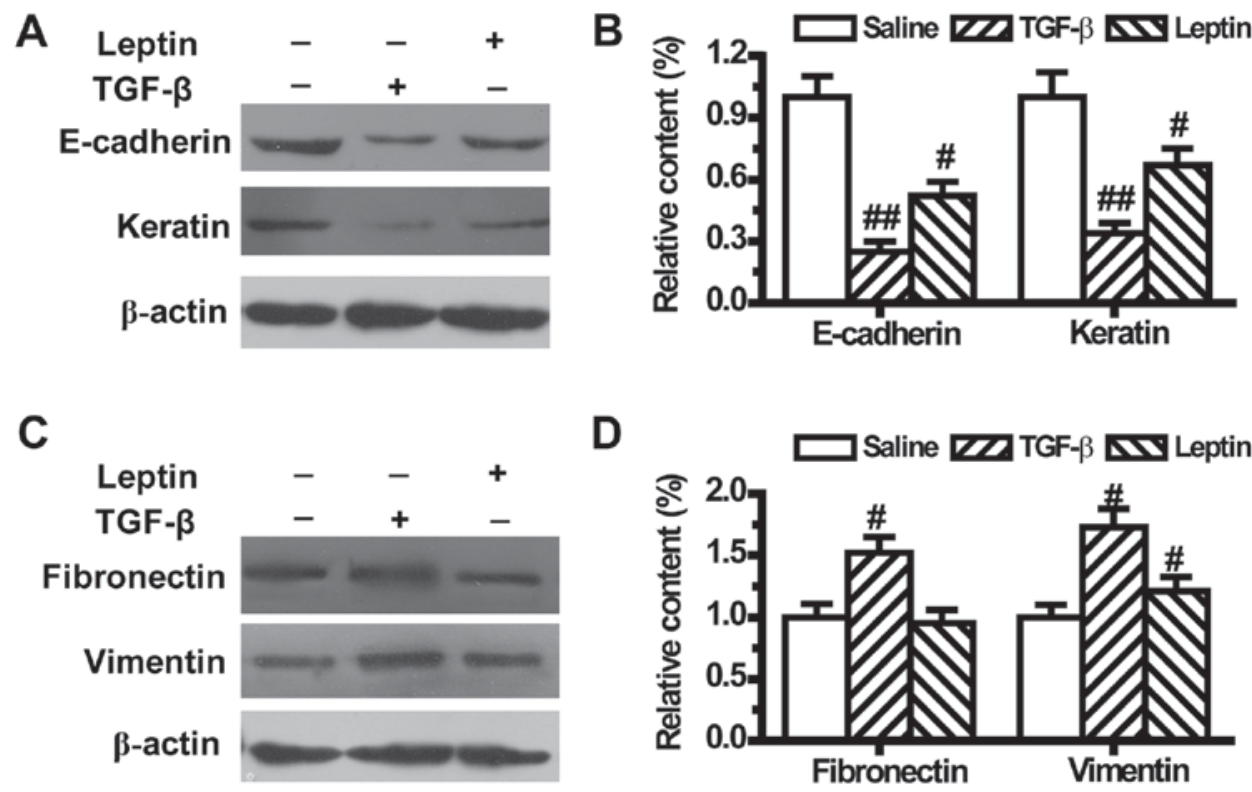

D

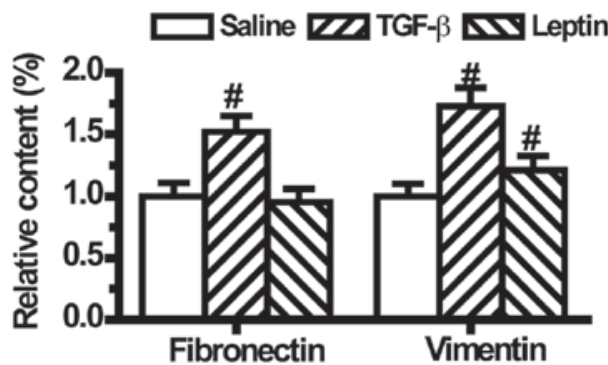

Figure 2. Leptin regulates the expression of epithelial-to-mesenchymal transition markers in A549 cells ( $\mathrm{n}=6$ ). The protein expression of (A) epithelial markers E-cadherin and Keratin and the (C) mesenchymal markers, Fibronectin and Vimentin were measured by western blot analysis after A549 cells were treated with TGF- $\beta 1$ or leptin for 48 h. (B) Relative content of E-cadherin and Keratin and (D) Fibronectin and Vimentin was calculated against $\beta$-actin. Values are expressed as mean \pm standard error of the mean. ${ }^{\#} \mathrm{P}<0.05,{ }^{\# \#} \mathrm{P}<0.01$ vs. the control group.

Leptin increases the expression levels of EMT-induced transcription factors in A549 cells. To confirm the mesenchymal phenotype, we assessed the expression levels of transcription factors of EMT such as ZEB-1 and Twist. Results from western blotting showed that ZEB-1 was significantly increased in the leptin and TGF- $\beta 1$ groups compared with the control group (Fig. 3A and B). The level of Twist was also upregulated by TGF- $\beta 1$ (Fig. 3A and C), but its level was not influenced by leptin (Fig. 3A and C).

Leptin activates EMT-related ERK signaling pathway in A549 cells. It has been reported that ERK and AKT pathways play an important role in modulating EMT. Therefore, the present study next investigated the effect of leptin on ERK and AKT activation in A549 cells. Our results showed that TGF- $\beta 1$ induced the activation of ERK and AKT, in accordance with results from previous reports, which was demonstrated by the upregulation of phosphorylated ERK and AKT (Fig. 4). In addition, leptin significantly increased the expression of phosphorylated ERK, which indicated activation of the ERK pathway (Fig. 4A and B). However, leptin did not change the expression of phosphorylated AKT (Fig. 4C and D).

Leptin enhances EMT-induced tumor phenotypes in A549 cells. Previous studies have shown that tumor cells with EMT phenotype are more motile resulting in increased migration, invasion and metastatic abilities (24). Although leptin induced EMT in A549 cells, whether leptin could regulate EMT-induced aggressive behaviors in A549 cells remained unclear. To investigate if leptin influences cell migration, the present study compared the migratory rate of the tumor cells in a wound-healing assay. We found that leptin significantly increased cell migration after wound induction for $24 \mathrm{~h}$ (Fig. 5A). Similarly, the cell invasion potential, which 


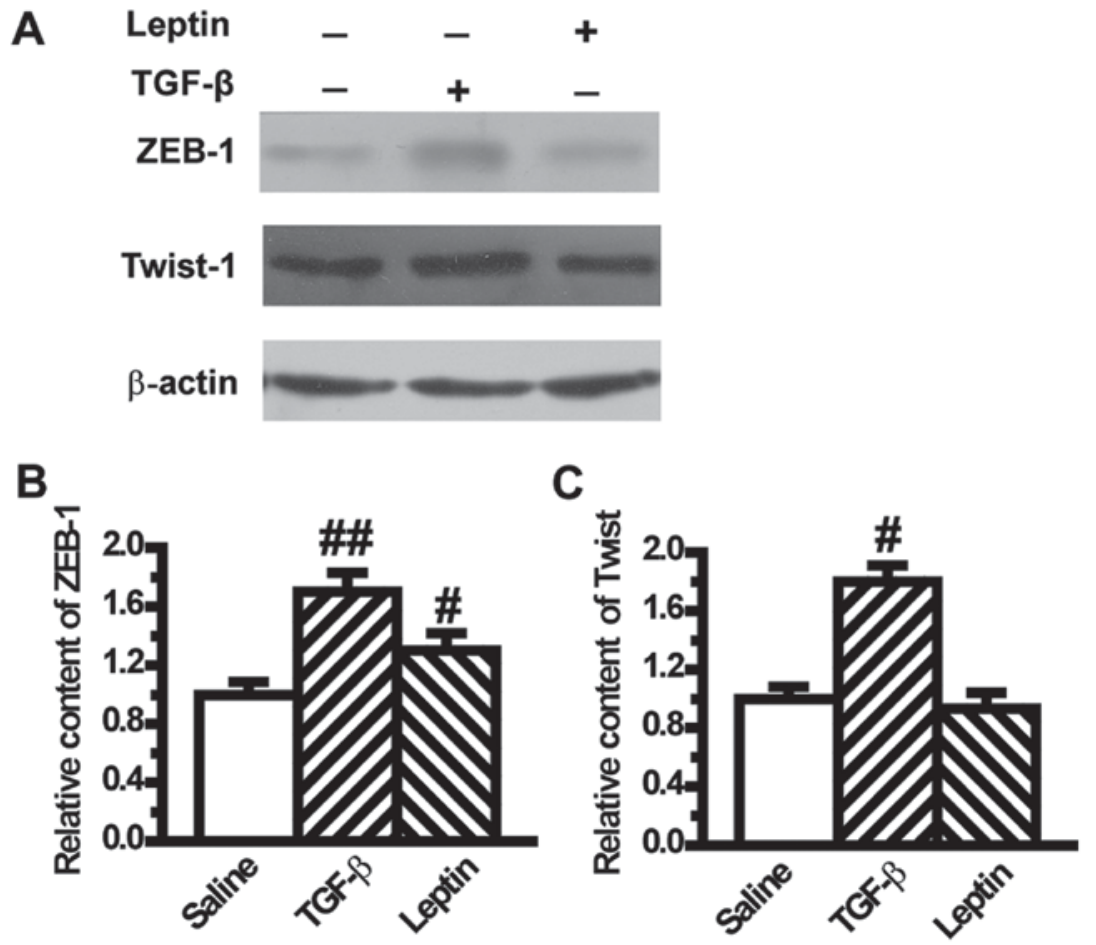

Figure 3. Leptin increases the expression of epithelial-to-mesenchymal transition-induced transcription factors in A549 cells (n=6). (A) Protein levels of ZEB-1 and Twist-1 were measured by western blot analysis after A549 cells were treated with TGF- $\beta 1$ or leptin for $48 \mathrm{~h}$. The relative content of (B) ZEB-1 and (C) Twist- 1 were calculated against $\beta$-actin. Values are expressed as mean \pm standard error of the mean. ${ }^{\#} \mathrm{P}<0.05,{ }^{\# \#} \mathrm{P}<0.01$ vs. the control group.

A

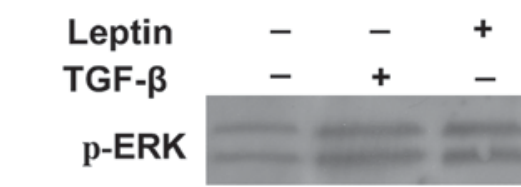

\section{Total-ERK}

$\beta$-actin

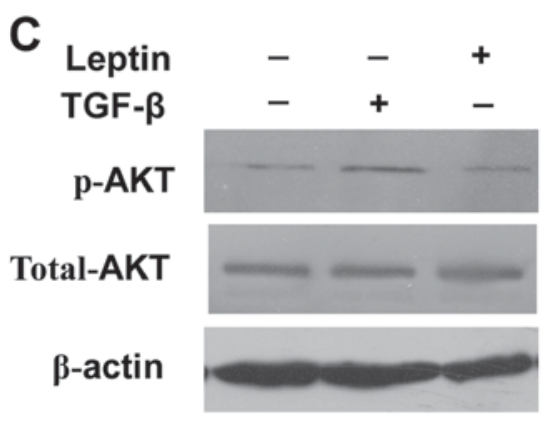

B
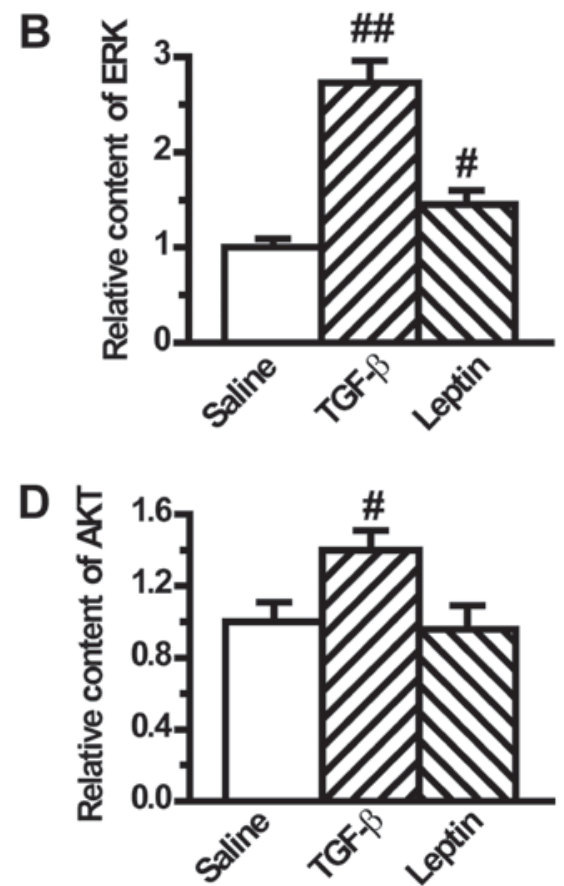

Figure 4. Leptin activates epithelial-to-mesenchymal transition-related ERK signaling pathway in A549 cells. (A) Protein levels of p-ERK and total-ERK were measured by western blot analysis after A549 cells were treated with TGF- $\beta 1$ or leptin for $48 \mathrm{~h}(\mathrm{n}=6)$. (B) The relative content of $\mathrm{p}$-ERK was calculated against $\beta$-actin. (C) Protein levels of p-AKT and total-AKT were measured by western blot analysis after A549 cells were treated with TGF- $\beta 1$ or leptin for $48 \mathrm{~h}$. (D) The relative content of $\mathrm{p}$-AKT was calculated against $\beta$-actin. Values are expressed as mean \pm standard error of the mean. ${ }^{\#} \mathrm{P}<0.05,{ }^{\# \#} \mathrm{P}<0.01 \mathrm{vs}$. the control group. AKT, protein kinase B; TGF, tumor growth factor; ERK, extracellular signal regulated kinase.

was measured in a Matrigel-coated Transwell assay, was significantly raised by leptin pretreatment (Fig. 5B). Moreover, the tumorigenic phenotype was also augmented by leptin as documented by the clonogenic growth assay (Fig. 5C). The regulatory mode of leptin was the same as that of TGF- $\beta 1$ (Fig. 5). 

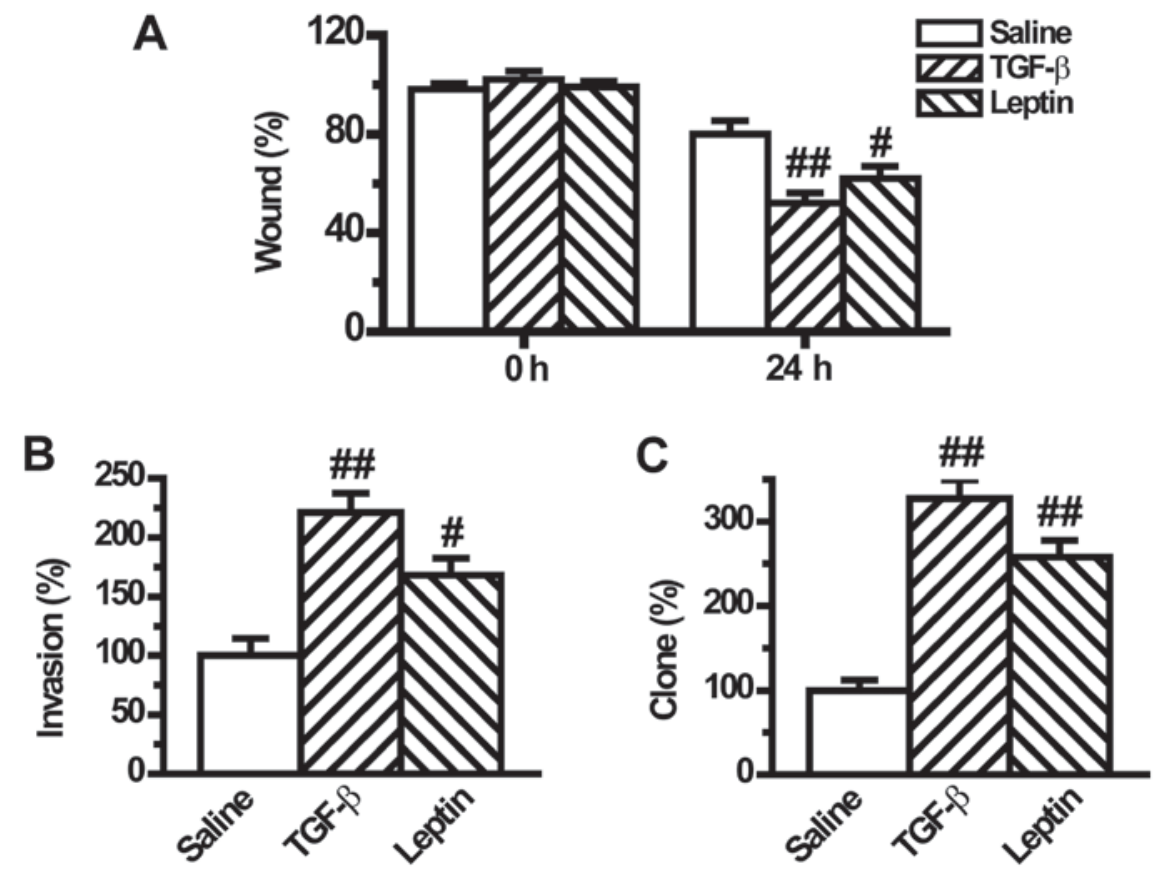

Figure 5. Leptin enhances epithelial-to-mesenchymal transition-induced tumor phenotypes in A549 cells (n=6). (A) Cell migration was measured by a woundhealing assay. The cells were incubated for $24 \mathrm{~h}$ after cell wounding and then the images were captured. (B) The invasive activity of cells was assayed by a Matrigel-coated Transwell assay. The cells that invaded through the filter were quantified $24 \mathrm{~h}$ following plating. Data were expressed relative to the invasive ability of the control cells. (C) The tumorigenic phenotype was measured by colony formation assay. All the plotted values are relative to A549 cells in the control group. Values are expressed as mean \pm standard error of the mean. ${ }^{\#} \mathrm{P}<0.05,{ }^{\# \#} \mathrm{P}<0.01$ vs. the control group.

\section{Discussion}

In the present study, we showed the important role of leptin in the development of EMT in A549 cells. First, we found that leptin could induce A549 cells to change from an epithelial phenotype to a mesenchymal phenotype. Second, leptin downregulated the expression levels of epithelial phenotype markers E-cadherin and Keratin and upregulated the expression of mesenchymal phenotype marker Vimentin in A549 cells. Third, leptin increased the expression of EMT-induced transcription factor ZEB-1 and the activation of ERK signaling pathway in A549 cells. Fourth, leptin enhanced EMT-induced cell migration, invasion and tumorigenic phenotypes in A549 cells. Together, these findings suggested that leptin is important in inducing EMT in A549 lung cells.

Leptin is mainly synthesized and secreted in white fat (25), but many other tissues also secrete a small amount of leptin. Leptin mainly functions in combination with its functional receptor $\mathrm{Ob}-\mathrm{R}$. The main role of leptin is to regulate metabolism by inducing anorexigenic factors and suppressing orexigenic neuropeptides (26). Moreover, recent reports suggest that leptin is involved in the regulation of immune function, reproduction, hematopoiesis, and blood pressure.

Studies have shown that leptin and its receptors are highly expressed in lung cancer tissues (27), and the leptin receptor gene polymorphism determines the susceptibility of NSCLC (28), indicating that the leptin pathway is related to the occurrence of lung cancer. In A549 cells cultured in vitro, leptin promotes the growth of lung cancer cells by inhibiting apoptosis (29), and promotes the immune escape of tumor cells by inducing proinflammatory cytokines and inhibiting apoptosis in cells (30). Leptin can promote the proliferation of A549 cells through blocking endoplasmic reticulum stressmediated apoptosis and this blocking is mediated by the p-Perk and ATF6 pathway through blocking the activation of CHOP $(29,31)$. Moreover, downregulation of leptin inhibits growth and induces apoptosis of lung cancer cells via the Notch and JAK/STAT3 signaling pathways, which suggests that leptin knockdown could become a new approach for the prevention of lung cancer progression (32). However, few studies have been reported to investigate the effect of leptin on invasion and migration and the underlying mechanisms in lung cancer cells. In the present study, we attempted to observe the involvement of a previously unknown mechanism, EMT, in the leptin-induced invasion and migration in A549 cells.

EMT is characterized by a switch from an epithelial phenotype of polarized cells expressing epithelial markers to a mesenchymal phenotype of cells with downregulation of epithelial markers and upregulation of mesenchymal markers that lack polarity and are motile. As EMT is a critical step in the development of metastases, it is an attractive target for anticancer therapeutic strategies (33). In the present study, we first investigated the effect of leptin on EMT in A549 cells. Results showed that leptin induced EMT in a similar way to TGF- $\beta 1$ in A549 cells, as proven by the morphological change (Fig. 1). The effect of leptin was further confirmed by the decrease in the expression levels of the epithelial phenotype markers E-cadherin and Keratin and the increase of the mesenchymal phenotype marker Vimentin (Fig. 2). Transcriptional factors such as ZEB-1 and Twist play a central role in EMT, which have been reported to serve as mesenchymal markers $(34,35)$. Then, we next examined whether leptin affected EMT-induced transcription factors. Our results demonstrated that expression of ZEB-1 was increased by leptin (Fig. 3). 
To mechanistically understand how leptin affected EMT, we investigated two main molecules, namely ERK and AKT, which are involved in the MAPK and PI3K/AKT pathways, respectively, and are key for EMT initiation and maintenance $(36,37)$. TGF- $\beta$ can activate Akt and ERK signaling pathways that are activated by tyrosine kinase receptors or other receptor types in response to their respective ligands (37). TGF- $\beta$-induced activation of Akt and ERK pathways has been linked to the characteristics of EMT, such as cytoskeletal organization, cell growth, survival, migration, and invasion (38). Our results showed that TGF- $\beta 1$ greatly increased the activation of ERK and AKT pathways (Fig. 4). Leptin activated the ERK signaling pathway and did not influence the AKT pathway in A549 cells. Theses results suggested that the activation of ERK was probably responsible for the induction of leptin-induced EMT.

EMT is able to increase cell adhesion, migration, invasion, tumorigenesis and drug resistance in cancer cells $(24,39,40)$. Therefore, we next investigated whether leptin could increase EMT-induced malignant phenotypes in A549 cells. Results from the wound-healing assay and Transwell assay indicated that leptin increased the movement and the migratory and invasive abilities of A549 cells (Fig. 5A and B). Furthermore, the clonogenic growth assay revealed that leptin also promoted tumorigenesis in lung cancer cells (Fig. 6C). These data suggested that leptin increased lung cancer cell invasion and metastasis by inducing EMT.

Consistent with the results of the present study, a previous report regarding the mechanism of leptin in the promotion of EMT leading to metastasis in A549 lung cancer cells was studied (21). In the previous study, the incidence of EMT in A549 cells was examined by real-time PCR and immunofluorescence staining. Furthermore, it was found that in patient samples leptin was present at higher levels in samples associated with diagnosis of lung cancer bone metastases tissue than lung cancer tissue. The results also indicated that leptin promoted the metastasis of A549 cell lines by inducing EMT in a TGF- $\beta$-dependent manner, which is another mechanism accounting for the effect of leptin on EMT.

Numerous studies in vivo have found that leptin is involved in tumorigenesis and the progression of lung cancer. The serum leptin level has been shown to increase in patients with NSCLC. When stratifying the groups according to the lung cancer histological subtypes, mean serum leptin level is significantly higher in patients with adenocarcinoma compared with squamous cell subtype (41). A meta-analysis indicated that a subgroup analysis in high-study quality group found a weak association between serum leptin concentration and lung cancer in the Chinese population (42). Another study showed that the expression levels of leptin and leptin receptor in primary pulmonary adenocarcinoma tissues were associated with their expression levels in bone metastatic tissue (43). Further results indicated that the serum leptin level had prognostic indications in patients with advanced lung adenocarcinoma during cisplatin/pemetrexed chemotherapy (44). However, these studies were inconsistent. Results found that patients present significantly lower serum leptin levels compared with control group $(45,46)$ and that the serum leptin level has no prognostic indications in advanced lung cancer patients (46). The reasons for the divergence may be interpreted that the selected population and the inclusion criteria were different. Based on the results obtained, the role of leptin in vivo has not been fully elucidated and further studies are required in order to clarify this.

In summary, the present study provides evidence that leptin induces EMT via activating the ERK pathway. Furthermore, leptin also increases EMT-induced invasion, metastasis and tumorigenic characteristics in lung cancer cells. At present, although further investigations are need to study the effects of leptin in vivo, our findings suggest that leptin may be a promising target for lung cancer treatment.

\section{Acknowledgements}

Not applicable.

\section{Funding}

This study was supported by the Natural Science Foundation of Shandong Province (grant nos. ZR2015HQ028 and ZR2015CQ015).

\section{Availability of data and materials}

The datasets analyzed during the current study are available from the corresponding author on reasonable request.

\section{Authors' contributions}

MX and FLC conceived and designed the study, and performed the cell culture and western blot analysis. NYL and XG collected the samples and performed the statistical analysis. XJS and XLJ performed the wound healing, Matrigel invasion and colony formation assays.

\section{Ethics approval and consent to participate}

Not applicable.

\section{Patient consent for publication}

Not applicable.

\section{Competing interests}

The authors declare that they have no competing interests.

\section{References}

1. Jemal A, Siegel R, Xu J and Ward E: Cancer statistics, 2010. CA Cancer J Clin 60: 277-300, 2010

2. Liu D, Yang Y and Zhao S: Autophagy facilitates the EGFR-TKI acquired resistance of non-small-cell lung cancer cells. J Formos Med Assoc 113: 141-142, 2014.

3. Petersen I and Petersen S: Towards a genetic-based classification of human lung cancer. Anal Cell Pathol 22: 111-121, 2001.

4. Ma J, Ward EM, Smith R and Jemal A: Annual number of lung cancer deaths potentially avertable by screening in the united states. Cancer 119: 1381-1385, 2013.

5. Jones SE: Metastatic breast cancer: The treatment challenge. Clin Breast Cancer 8: 224-233, 2008.

6. Bacac M and Stamenkovic I: Metastatic cancer cell. Annu Rev Pathol 3: 221-247, 2008. 
7. Chaffer CL and Weinberg RA: A perspective on cancer cell metastasis. Science 331: 1559-1564, 2011.

8. Thiery JP: Epithelial-mesenchymal transitions in tumour progression. Nat Rev Cancer 2: 442-454, 2002.

9. Kalluri R and Weinberg RA: The basics of epithelial-mesenchymal transition. J Clin Invest 119: 1420-1428, 2009.

10. Tomaskovic-Crook E, Thompson EW and Thiery JP: Epithelial to mesenchymal transition and breast cancer. Breast Cancer Res 11: 213, 2009

11. Yilmaz M, Christofori G and Lehembre F: Distinct mechanisms of tumor invasion and metastasis. Trends Mol Med 13: 535-541, 2007.

12. Jarde T, Caldefie-Chezet F, Damez M, Mishellany F, PenaultLlorca F, Guillot J and Vasson MP: Leptin and leptin receptor involvement in cancer development: A study on human primary breast carcinoma. Oncol Rep 19: 905-911, 2008.

13. Liu CL, Chang YC, Cheng SP, Chern SR, Yang TL, Lee JJ, Guo IC and Chen CP: The roles of serum leptin concentration and polymorphism in leptin receptor gene at codon 109 in breast cancer. Oncology 72: 75-81, 2007.

14. Otvos L Jr and Surmacz E: Targeting the leptin receptor: A potential new mode of treatment for breast cancer. Expert Rev Anticancer Ther 11: 1147-1150, 2011.

15. Akinci M, Kosova F, Cetin B, Aslan S, Ari Z and Cetin A: Leptin levels in thyroid cancer. Asian J Surg 32: 216-223, 2009.

16. Uddin S, Bu R, Ahmed M, Hussain AR, Ajarim D, Al-Dayel F, Bavi P and Al-kuraya KS: Leptin receptor expression and its association with pi3k/akt signaling pathway in diffuse large b-cell lymphoma. Leuk Lymphoma 51: 1305-1314, 2010.

17. Kitade M, Yoshiji H, Kojima H, Ikenaka Y, Noguchi R, Kaji K, Yoshii J, Yanase K, Namisaki T, Asada K, et al: Leptin-mediated neovascularization is a prerequisite for progression of nonalcoholic steatohepatitis in rats. Hepatology 44: 983-991, 2006.

18. Ribatti D, Belloni AS, Nico B, Di Comite M, Crivellato E and Vacca A: Leptin-leptin receptor are involved in angiogenesis in human hepatocellular carcinoma. Peptides 29: 1596-1602, 2008.

19. Chia VM, Newcomb PA, Lampe JW, White E, Mandelson MT, McTiernan A and Potter JD: Leptin concentrations, leptin receptor polymorphisms and colorectal adenoma risk. Cancer Epidemiol Biomark Prev 16: 2697-2703, 2007.

20. Stolzenberg-Solomon RZ, Newton CC, Silverman DT, Pollak M, Nogueira LM, Weinstein SJ, Albanes D, Mannisto S and Jacobs EJ: Circulating leptin and risk of pancreatic cancer: A pooled analysis from 3 cohorts. Am J Epidemiol 182: 187-197, 2015.

21. Feng H, Liu Q, Zhang N, Zheng L, Sang M, Feng J, Zhang J, $\mathrm{Wu} X$ and Shan B: Leptin promotes metastasis by inducing an epithelial-mesenchymal transition in a549 lung cancer cells. Oncol Res 21: 165-171, 2013

22. Kim JH, Jang YS, Eom KS, Hwang YI, Kang HR, Jang SH, Kim CH, Park YB, Lee MG, Hyun IG, et al: Transforming growth factor betal induces epithelial-to-mesenchymal transition of a549 cells. J Korean Med Sci 22: 898-904, 2007.

23. Kasai H, Allen JT, Mason RM, Kamimura T and Zhang Z: TGF-betal induces human alveolar epithelial to mesenchymal cell transition (EMT). Respir Res 6: 56, 2005.

24. Zhang HJ, Wang HY, Zhang HT, Su JM, Zhu J, Wang HB, Zhou WY, Zhang H, Zhao MC, Zhang L, et al: Transforming growth factor- $\beta 1$ promotes lung adenocarcinoma invasion and metastasis by epithelial-to-mesenchymal transition. Mol Cell Biochem 355: 309-314, 2011

25. Malli F, Papaioannou AI, Gourgoulianis KI, Daniil Z and Daniil Z: The role of leptin in the respiratory system: An overview. Respir Res 11: 152, 2010.

26. Lago F, Dieguez C, Gomez-Reino J and Gualillo O: Adipokines as emerging mediators of immune response and inflammation. Nat Clin Pract Rheumatol 3: 716-724, 2007.

27. Xu YJ, Shao YF, Zhao X, Geng YT, Wang K and Yin YM Expression and clinical significance of leptin, the functional receptor of leptin $(\mathrm{OB}-\mathrm{Rb})$ and her-2 in non-small-cell lung cancer: A retrospective analysis. J Cancer Res Clin Oncol 137: $1841-1848,2011$
28. Li Y, Geng J, Wang Y, Lu Q, Du Y, Wang W and Li Z: The role of leptin receptor gene polymorphisms in determining the susceptibility and prognosis of nsclc in chinese patients. J Cancer Res Clin Oncol 138: 311-316, 2012.

29. Wang W, Yan H, Dou C and Su Y: Human leptin triggers proliferation of a549 cells via blocking endoplasmic reticulum stress-related apoptosis. Biochemistry 78: 1333-1341, 2013.

30. Shen Y, Wang Q, Zhao Q and Zhou J: Leptin promotes the immune escape of lung cancer by inducing proinflammatory cytokines and resistance to apoptosis. Mol Med Rep 2: 295-299, 2009.

31. Lai Q and Sun Y: Human leptin protein induces proliferation of A549 cells via inhibition of PKR-like ER kinase and activating transcription factor-6 mediated apoptosis. Yonsei Med J 54: 1407-1415, 2013

32. Zheng XJ, Yang ZX, Dong YJ, Zhang GY, Sun MF, An XK, Pan LH and Zhang SL: Downregulation of leptin inhibits growth and induces apoptosis of lung cancer cells via the notch and jak/stat3 signaling pathways. Biol Open 5: 794-800, 2016

33. Qi HW, Xin LY, Xu X, Ji XX and Fan LH: Epithelial-tomesenchymal transition markers to predict response of berberine in suppressing lung cancer invasion and metastasis. J Transl Med 12: 22, 2014

34. Sanchez-Tillo E, Lazaro A, Torrent R, Cuatrecasas M, Vaquero EC, Castells A, Engel P and Postigo A: Zeb1 represses e-cadherin and induces an emt by recruiting the swi/snf chromatin-remodeling protein brg1. Oncogene 29: 3490-3500, 2010.

35. Yang MH, Hsu DS, Wang HW, Wang HJ, Lan HY, Yang WH, Huang $\mathrm{CH}$, Kao SY, Tzeng CH, Tai SK, et al: Bmil is essential in Twist1-induced epithelial-mesenchymal transition. Nat Cell Biol 12: 982-992, 2010

36. Chen XF, Zhang HJ, Wang HB, Zhu J, Zhou WY, Zhang H, Zhao MC, Su JM, Gao W, Zhang L, et al: Transforming growth factor- $\beta 1$ induces epithelial-to-mesenchymal transition in human lung cancer cells via PI3K/Akt and MEK/Erk1/2 signaling pathways.. Mol Biol Rep 39: 3549-3556, 2012.

37. Bakin AV, Tomlinson AK, Bhowmick NA, Moses HL and Arteaga CL: Phosphatidylinositol 3-kinase function is required for transforming growth factor beta-mediated epithelial to mesenchymal transition and cell migration. J Biol Chem 275: 36803-36810, 2000.

38. Derynck R and Zhang YE: Smad-dependent and smad-independent pathways in tgf-beta family signalling. Nature 425: 577-584, 2003.

39. Ahmad A, Maitah MY, Ginnebaugh KR,Li Y, Bao B, Gadgeel SM and Sarkar FH: Inhibition of hedgehog signaling sensitizes nsclc cells to standard therapies through modulation of emt-regulating mirnas. J Hematol Oncol 6: 77, 2013.

40. Gomes LR, Terra LF, Sogayar MC and Labriola L: Epithelialmesenchymal transition: Implications in cancer progression and metastasis. Curr Pharm Biotechnol 12: 1881-1890, 2011.

41. Karatas F, Yalcin B, Sahin S, Akbulut H, Utkan G, Demirkazik A and Icli F: The significance of serum leptin level in patients with early stage nonsmall cell lung cancer. J Cancer Res Ther 13 : 204-207, 2017.

42. Tong X, Ma Y, Zhou Q, He J, Peng B, Liu S, Yan Z, Yang X and Fan H: Serum and tissue leptin in lung cancer: A meta-analysis. Oncotarget 8: 19699-19711, 2017.

43. Feng HL, Guo P, Wang J, Liu QY, Xu JF, Yang HC and Zhang JM: Association of the expression of leptin and leptin receptor with bone metastasis in pulmonary adenocarcinoma. Zhonghua Zhong Liu Za Zhi 38: 840-844, 2016 (In Chinese).

44. Mou W, Xue H, Tong H, Sun S, Zhang Z, Zhang C, Sun Q, Dong J, Wen X, Yan G, et al: Prognostic value of serum leptin in advanced lung adenocarcinoma patients with cisplatin/pemetrexed chemotherapy. Oncol Lett 7: 2073-2078, 2014.

45. Demiray G, Degirmencioglu S, Ugurlu E and Yaren A: Effects of serum leptin and resistin levels on cancer cachexia in patients with advanced-stage non-small cell lung cancer. Clin Med Insights Oncol 11: 1179554917690144, 2017.

46. Anar C, Deniz D, Erol S, Batum O, Bicmen C and Yilmaz U: Are serum leptin levels a prognostic factor in advanced lung cancer? Bratisl Lek Listy 118: 13-16, 2017. 